This is the pre-print version of the following article: Heeks, R. "The approach of senior public officials to information technology-related reform: lessons from India", Public Administration and Development, 20, 197-205, 2000, which has been published in final form at: http://onlinelibrary.wiley.com/doi/10.1002/1099162X(200008)20:3\%3C197::AID-PAD109\%3E3.0.CO;2-6/abstract

\title{
The approach of senior public officials to information technology-related reform: lessons from India
}

\author{
RICHARD HEEKS* \\ Institute for Development Policy and Management, University of Manchester
}

\begin{abstract}
SUMMARY
A review of global experience suggests that information technology (IT) has great potential to contribute to public sector reform. However, the Indian reality - like that for many countries - has been more problematic, with many failures of IT-related reform; failures that can be described as total, partial, or failures of sustainability and replication. Many factors help explain such failure, but a key component is the approach to IT and reform adopted by senior public officials. A 'four Is' model of approaches is described: the non-IT approach of 'ignore', and the IT-related approaches of 'isolate', 'idolise' and 'integrate'. Analysis of Indian cases suggests it is the last approach that is most likely to deliver reform objectives; yet it remains the least commonly-adopted. Changes are therefore required in current strategies for public administration training and in the planning and management of change.
\end{abstract}

\section{INTRODUCTION: THE POTENTIAL OF INFORMATION TECHNOLOGY TO SUPPORT REFORM}

Government has been, and still remains, the single largest collector, user, holder and producer of information ${ }^{1}$. Information is a central resource for all staff levels and for all activities: 'In pursuing the democratic/political processes, in managing resources, executing functions, measuring performance and in service delivery, information is the basic ingredient' (Isaac-Henry, 1997, p.132)

The work of the public sector is thus very information-intensive, and four main types of formal information are identifiable:

\footnotetext{
* Dr Heeks is a Senior Lecturer at the Institute for Development Policy and Management, University of Manchester, Precinct Centre, Manchester, M13 9GH, UK. Correspondence to: richard.heeks@man.ac.uk

${ }^{1}$ Information may be defined as 'data that has been processed to make it useful to its recipient'. It is thus differentiated from data ('raw, unprocessed information') and knowledge ('information that has been assimilated into a coherent framework of understanding: usually the human mind') (Heeks, 1998). Government has often been better at handling data than at handling information. For the sake of consistency, however, the term 'information' will be used throughout this article.
} 
- Information to support internal management. This includes information about staff for personnel management, and information about budgets and accounts for financial management. Like the other types of information described here, it can be used for everything from day-to-day operational implementation up to long-term policy analysis and planning.

- Information to support public administration and regulation. This includes information that records details of the main 'entities' in a country: people, business enterprises, buildings, land plots, imports/exports, etc. It is used for a variety of purposes such as legal, commercial and fiscal.

- Information to support public services. Examples include education (e.g. school staff records), health (e.g. patient records), transport (e.g. passenger reservation information) and public utilities (e.g. customer billing information).

- Information made publicly available. This includes:

- Information the public sector wishes to disseminate such as press releases, consultation papers, details of policies, laws and regulations, and details of benefits and entitlements.

- Information the public sector collects that it may make available, such as demographic or economic statistics.

- Information the public sector is required to supply such as audited accounts, internal policy documents and correspondence, and responses to requests from politicians or journalists or citizens.

Given this information-intensity, changes in information systems (IS) must be an essential part of all public sector reform initiatives, and changes in information technology (IT) will also have a great potential ${ }^{2}$. This potential contribution of IT to public sector reform can be illustrated by the following examples from around the world:

- Increased efficiency. IT can reduce the cost and/or time required for organisational activities, and therefore increase process productivity. In the US, the Lawrence Livermore National Laboratory developed a World Wide Web-based system to reduce the cost and increase the speed of parts procurement (Gebauer and Schad, 1998). As a result, the efficiency of the organisation's supply processes was increased with time savings of up to $90 \%$ and major cost reductions.

- Decentralisation. IT can provide support for more efficient and effective decision making at decentralised locations and create new information flows that incorporate those locations. In Ireland, the Department of Social Welfare created more than a dozen computerised applications in order to support the decentralisation of responsibilities from Dublin to outlying offices (Cooney and O'Flaherty, 1996).

- Increased accountability. IT can create new accountability information and can deliver accountability information to new recipients, providing for more efficient or effective accountability. In the US, 'collusion detection software' was developed to root out impropriety in bids and awards for public works and contracts by statistical

\footnotetext{
${ }^{2}$ It is valuable to understand the difference in terms. IT is 'computing and telecommunications technologies that provide automatic means of handling information' (Heeks, 1998). IS are 'systems of human and technical components that accept, store, process, output and transmit information. They may be based on any combination of human endeavours, paper-based methods and IT.' (ibid.) IT on its own therefore does not do anything useful; this only happens with the addition of information, people and processes to create an information system.
} 
analysis of pricing information (Anthes, 1993). Use by the federal government has led to dozens of convictions for fraudulent bidding and contract award.

- Improved resource management. IT can create new performance information and deliver it to decision makers, providing more effective managerial control over government resources. In Malaysia, government development authorities collaborated to develop a computerised system to facilitate land resource management (Raman and Yap, 1996). This has led to better decision making about the location of new industrial, agricultural and residential sites.

- Customer orientation. IT can form the conduit for delivery of new forms of public service. 'In Spain and Portugal, smart cards are issued to people to claim unemployment benefit at kiosks, and to check on job vacancies and training opportunities.' (Gosling, 1997, p.69). This has improved service delivery performance and raised satisfaction ratings of public sector clients.

\section{INDIAN REALITIES OF IT-RELATED REFORM}

Globally, then, new information technology has demonstrated a potential to help support and even drive forward the process of public sector reform. But, moving on from the issue of potential, what are the realities of IT-related reform ${ }^{3}$ in developing countries? India was chosen as a case example in order to investigate this question ${ }^{4}$.

Objective reporting of IT-related reform cases in India (and elsewhere) is rare. Many reports are written from a 'rose-tinted' viewpoint by those with a vested interest in the reform initiative. Their glowing and uncritical claims of success frequently bear little relation to reality. Nonetheless, reliable cases can be found and one can place these into three categories.

\section{Success}

Computerisation of the Indian Railways' Passenger Reservation System may be branded a success (Heeks, 1996a). Not only did it significantly increase the efficiency of the reservation process, but it also reduced corruption (though did not eliminate it), increased rail staff morale, and improved the quality of customer service. Beyond these reform components, it also gave Indian Railways (and India more widely) a more modern image, and it helped to build IT capabilities within the country. Sadly, this case remains almost a lone beacon in India which 'seems to stand out as a solitary example of success.' (Bhatnagar, 1997, p.5).

\section{Open Verdict}

\footnotetext{
${ }^{3}$ The term 'IT-related reform' refers here to reform initiatives in which IT has some role, regardless of whether that role is positive or negative, and regardless of whether the initiative succeeds or fails. In relation to the model presented later in this article, the term therefore covers the isolate, idolise and integrate approaches.

${ }^{4}$ India was selected because of its relatively long and broad interaction with IT. The country has been a significant IT consumer since the mid-1950s and a significant IT producer since the early 1970s. A clear link between computing and reform of Indian public administration has been made since Rajiv Gandhi's first period as Prime Minister, from 1984. This has continued to date with India's IT Action Plan, in operation since 1998
} 
A few ongoing IT-related reform projects have yet to fall clearly into the categories of either success or failure. Perhaps the best-known of these is CRISP, the Computerised Rural Information Systems Project. When initially analysed, after some five years of operation, this appeared to have made little impact and to be heading for failure (Madon, 1993). Subsequent analysis, however, revealed 'sparks of life' within the project, with some computers being used to support analytical management decision making, thereby enabling decentralisation and improved delivery of assistance (Madon and Sahay, 1996).

\section{Failure}

By far the largest category of reports - both from the formal literature and from the dozens of Indian public servants trained each year by the author - is that of failure. There are no cast-iron statistics on this and there are unlikely ever to be. Nonetheless, based on the available evidence, one can state with some degree of certainty that the majority of IT-related reform initiatives in India end in failure. This may be the total failure of an initiative never implemented or in which a new system is implemented but immediately abandoned; the partial failure of an initiative in which major goals are unattained or in which there are significant undesirable outcomes; the sustainability failure of an initiative that succeeds initially but then fails after a year or so; or the replication failure of an initiative that succeeds in one place but cannot be repeated elsewhere.

Formally-reported examples include the following:

- Total failure. The Director of Adult Education in the National Literacy Mission Authority was smitten by the potential of IT to improve the management of literacy programmes (Jain, 1994). Having seen a software firm's demonstration, and despite glaring technical and data constraints that were obvious to any neutral observer, he commissioned a complex executive information system (EIS) that soon fell squarely into the 'total failure' category.

- Partial failure. Part of the Income Tax Department's tax system was computerised. The project ran into difficulties due to political antagonisms between various groups; notably between regional tax commissioners and the central tax board, and between management and unions. As a result, only parts of the information system and only a sub-set of intended process reforms became operational and even these were resisted by staff. There was therefore only very limited achievement of reform objectives (Singh, 1990).

- Sustainability failure. A computerised decision support system(DSS) was created for the Narmada Irrigation Project Authority (Rama Rao, 1990). The system was initially used to increase efficiency by helping engineers save time in their cost estimations of canal engineering work. However, the system was never properly used for its main intended purpose: the production of improved canal design. Upon retirement of the Chief Engineer who had championed use of the DSS, even the estimation use was discontinued. 
- Replication failure. A computerised management information system was developed in Surendranagar district, Gujarat state. It was used to demonstrate the feasibility of providing computer support to planning and monitoring tasks at the district level, thereby enabling decentralisation (Bhatnagar, 1992). Although the system proved useful, it was never adopted elsewhere because other district officers had a 'not invented here' mentality that rejected innovations made by anyone other than themselves.

\section{UNDERSTANDING IT-RELATED REFORM FAILURE IN THE INDIAN CONTEXT}

India and the public sector are not, of course, alone is suffering high rates of information systems failure (Heeks and Bhatnagar, 1999). However, given the frustration of reform objectives, one is naturally drawn to analyse why these failures are occurring in India.

There are almost as many explanations for failure as there are information systems. From these explanations, though, one can differentiate two main types of approach. The first posits a general model for failure (e.g. Sauer 1993, Heeks 1999a). The second identifies particular factors which are seen to be important in particular contexts. Here, we follow the second approach, focusing on factors of importance to the context of the public sector in developing countries.

Some analyses of this context highlight technical factors as contributing to failure (e.g. Uttamchandani, 1990; Guenat, 1992). However, a greater number highlight human/social factors. From within the 'human/social' range, one key factor emerges again and again from case study analysis as helping to determine IS success and failure in the public sector of developing countries (Gupta, 1996; Bhatnagar, 1997; Peterson, 1998). This is the attitude and actions of senior public officials, both politicians and managers. Peterson (1998, p.44), for example, states 'The most important factor in the success of an information system is a progressive senior officer who is willing to shoulder the risk of changing the organization and nurture the information system until it is revered and feared.'

In seeking to understand IT-related reform failure in the Indian public sector, it was therefore decided to make a specific examination of this particular factor: the role of senior officials. The generic role of such officials in organisational change has been investigated before (e.g. Korac-Kakabadse et al., 1996; Wallis and Dollery, 1997). Investigation here therefore focused on the specific attitude and approach that officials take to information technology and to its role in the reform process. 


\section{A MODEL OF OFFICIALS' APPROACHES TO IT'S ROLE IN REFORM}

Based on discussions with Indian public sector officials and their subordinates, and a review of relevant cases, a model emerged. Christened the 'four Is' model, it identifies the different approaches to IT's role in reform that appear over time, as described below.

\section{The 'Ignore' Approach: Non-IT-Related Reform}

In this case, public officials are ignorant about IT and information systems. They therefore do not include consideration of either in their plans for reform. IT expenditure is minimal or non-existent. Since this approach does not consider a role for IT in reform, it will not form a major focus of this article. Nevertheless, this approach is still found in many - perhaps even most - Indian public sector organisations. This is sometimes even so when computers are present for, in some cases, those computers remain unused and merely act as costly 'executive paperweights'.

\section{The 'Isolate' Approach: IT-Independent Reform}

In this approach, public officials remain computer-illiterate and lack an understanding of information's role. They nevertheless are aware of IT and its potential. Investment in IT is therefore included in reform plans but is seen as the separate responsibility of 'computer experts'. It is mainly associated with automation and some (often spurious or concocted) idea that efficiency gains will result. For other reform agendas, it is added as an afterthought and is not linked in any systematic way to the process of reform.

Both the early years of the CRISP project and the Indian Income Tax project cited above are examples of the isolate approach. In these cases, the introduction of computers was seen as the responsibility of technical staff rather than being something in which mainstream managers should become involved. As a result, huge investments made very little, if any, contribution to reform agendas in these Indian public sector organisations.

This approach should not be seen as some historical aberration for it can still be found. The recent Asian Development Bank-supported project for restructuring of Gujarat's financial sector provides an example:

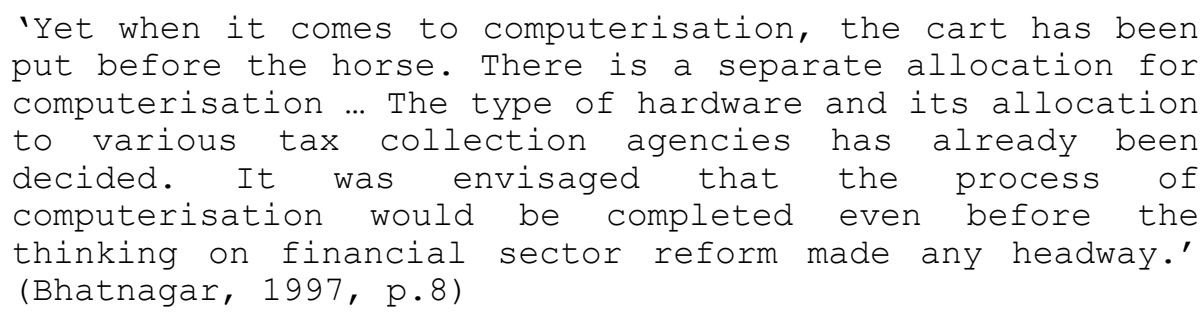


In this approach, public officials have become semi-literate. They use computers and are over-aware of IT's potential. They believe that IT can transform the business of government (or at least transform their own career/political prospects if they are seen to initiate a high-profile IT project). They are dimly aware that information is something important. The public sector becomes awash with IT-driven reform projects which place technology at the heart of the change process.

This approach has recently leapt to prominence thanks to N. Chandrababu Naidu, Chief Minister of Andhra Pradesh state. In 1997, he launched a high-profile project the LEAP21 (Leadership and Excellence in Andhra Pradesh in the twenty-first century) initiative - that exactly fits the idolise description. This initiative aims to use IT as a main lever in the creation of better government in Andhra Pradesh and, more generally, 'focuses ... on using Information Technology as a strategic tool for improving the quality of life for the people of Andhra Pradesh.' (Naidu, 1997, p.1).

The jury currently remains out on LEAP21. Chief Minister Naidu's intention of using state promotional interventions to support the development of the IT industry and IT technological capabilities is based on sound historical precedent (Heeks, 1996b). However, his hopes of driving public sector reform with IT are not. There is a long history of failure to deliver reform objectives via technology-driven projects, of which the literacy EIS case cited above is but one example (Kraemer et al., 1981; Davies, 1997).

Even where technology-centred projects initially appear to succeed in delivering reform objectives, Bhatnagar (1997) warns that they may not be sustainable or replicable since they so often depend on a single 'idolising' figurehead. When that senior official transfers to a new post, the project often collapses; when other organisations try to copy, failure ensues because the originator's drive or skills are lacking; and copying rarely takes place because 'a replication will never attract the same attention as a first time use' (Bhatnagar, 1997, p.6). In all situations, the cause is the lack of the original champion.

Examples of these sustainability and replication failures from India include the canal design and district administration cases cited above, and another DSS used to support improved planning of resource usage in two zonal railways which was never used in other zones (Ramani, 1994). With LEAP21 so focused on Naidu himself, prospects are limited for the sustainability and replication of any successes it may fortuitously achieve.

Simply calling for more champions of IT-related reform is not, therefore, enough. The presence of such champions may be a necessary factor, but what also matters is the approach they take. Having an 'idolising' champion may be as problematic for reform as having no champion at all. 
In this approach, public officials have become information-literate. They recognise information as a key organisational resource that is central to all public sector functions. IT is relegated to a secondary role: it is seen as a valuable means to achieve certain reform ends, not as an end in itself. The redesign of information systems and the introduction of IT are now fully integrated into the process of organisational change, driven by reform objectives.

The integrated approach therefore places information in the driving seat, relegating technology to an important but enabling role. In very simple terms, we can see four main steps in initiation of this approach:

1. Acceptance by key stakeholders of the need for reform.

2. Identification and communication of an agenda for reform.

3. Identification of the new and/or redesigned information systems requirements of this reform agenda.

4. Identification of the role, if any, that information technology has to play in meeting these requirements.

The successful computerisation of passenger reservations on Indian Railways can be seen to have followed this route. This originally involved a manual system of paper ledgers with reservations for one train held by one clerk at one booking window. Typically queuing time was two-three hours to make a reservation. After computerisation, any train could be reserved by any clerk at any window. Typical queuing time dropped to less than ten minutes. As noted above, corruption and ticket touting were also reduced and staff morale increased.

Despite undeniable hiccups, this project was kept on track thanks to a vision of efficiency, accountability and customer service objectives that was shared by key stakeholders, not held by just one champion. During the critical implementation period, these key stakeholders included politicians, such as the Prime Minister and the Railways Minister, and senior civil servants within the Ministry of Railways. All of them saw reservations as a key 'interface' between citizens and the public sector. They therefore drove on the reforms, recognising the significant improvements in public image and support that could be achieved from relatively low-cost changes to the reservation process.

This reform agenda was readily communicated to, and accepted by, other groups involved. Stationmasters and other managerial staff saw the changes as helping reduce corruption and complaints arising from reservations. Front-line clerical staff also wanted to change from dealing with a tired and abusive public in a practically Dickensian setting.

This need for reform had been understood since at least the mid-1970s, with an agenda of modernisation widely discussed and the need for rationalisation of systems to 
escape the old 'one-train-per-clerk' situation widely accepted (Jain and Raghuram, 1992). Information technology was then identified in the mid-1980s as the servant of this pre-existing reform agenda, not as the master of reform. As a result, technology solutions were shaped to fit reform objectives rather than vice versa, as is so often the case in examples of the idolise approach.

However, other examples of the integrated approach hardly exist in India. Approaches and chronologies remain unevenly distributed in India, but Bhatnagar (1997) sees much of the public sector still struggling to move away from the ignore stage. If anything, it seems likely to move on to 'idolise', as exemplified by the LEAP21 initiative, rather than 'integrate'.

\section{CONCLUSION}

Information systems change has always been an essential part of all organisational change in the public sector (though this may not have been well recognised at times). Information technology is becoming an increasingly important part of such IS change, and is now seen to have great potential to contribute to the reform process.

Many factors underlie success and failure of IT-related reforms. However, senior public officials are a key element. This study of India shows that they can take different approaches in trying to realise the potential of information and IT. These approaches are summarised in Table 1.

Table 1. Summary of Approaches to IT's Role in Public Sector Reform

\begin{tabular}{|l|l|l|l|l|}
\hline Approach & $\begin{array}{l}\text { Role of IT } \\
\text { in Reform }\end{array}$ & $\begin{array}{l}\text { Role of IS in } \\
\text { Reform }\end{array}$ & $\begin{array}{l}\text { Delivery of } \\
\text { Reform Objectives }\end{array}$ & Prevalence \\
\hline Ignore & None & Unrecognised & Weak & $\begin{array}{l}\text { Widespread, but } \\
\text { declining }\end{array}$ \\
\hline Isolate & Peripheral & Unrecognised & Weak & $\begin{array}{l}\text { Relatively limited, } \\
\text { perhaps static }\end{array}$ \\
\hline Idolise & Primary role & $\begin{array}{l}\text { Limited } \\
\text { recognition }\end{array}$ & Weak & $\begin{array}{l}\text { Limited, probably } \\
\text { growing }\end{array}$ \\
\hline Integrate & Enabler & $\begin{array}{l}\text { Central role } \\
\text { recognised }\end{array}$ & Strong & $\begin{array}{l}\text { Very limited, } \\
\text { growth constrained }\end{array}$ \\
\hline
\end{tabular}

Despite the potential for IT to support reform, there remain substantial problems a) for the public sector of developing countries to enter the IT-related reform era at all; and b) for it to move on within that era to an integrated approach that will use IT to effectively enable delivery of reform objectives.

There is no magic recipe for ensuring widespread use of the integrated approach but education and training must surely form a substantial part of the package. Yet review 
of current public administration training programmes in India shows that most can be described as 'ignore going on idolise' in their approach. There is little attempt to build the hybrid managers - spanning managerial, IT and IS skills - that an IT-enabled public sector requires (Mundy et al., 1999). These skill sets remain unintegrated within current training and often ignored. Some potential public employees and in-service trainees may gain computing skills on their training programmes, but they do not gain information or information systems knowledge and skills. Any view of IT beyond the hands-on is typically simplistically-positive.

Not only does this hamper integrated approaches today, it also hints at a dangerously self-reinforcing spiral. If the present generation of Indian public officials cannot value or manage information, that sets the 'information-blind' agenda for current training and debate, thus ensuring that the next generation, too, will be unable to value or manage information. A similar spiral runs the risk of developing a 'blinded by computers' agenda of IT idolatry.

The idolise approach starts by asking, 'What opportunities does IT provide?', and then uses this to create a set of opportunistic, technology-driven reform initiatives. By contrast, adopting the integrated approach means that Indian public officials must take a more strategic approach to change; an approach that drives technology requirements from information systems requirements, and information systems requirements from strategic reform objectives (see Figure 1).

Figure 1. The Integrated Approach to IT and Reform

\begin{tabular}{|c|}
\hline Strategic \\
Reform \\
Objectives
\end{tabular}$\longrightarrow$\begin{tabular}{|c|c|} 
Information \\
System \\
Plans
\end{tabular}$\longrightarrow \begin{gathered}\text { Information } \\
\text { Technology } \\
\text { Plans }\end{gathered}$

Strategic information systems planning of this type is very much in vogue in the private sector, though the application of such techniques in practice and in the public sector remains questionable (Ballantine and Cunningham, 1999). Perhaps more realistic is a 'core-periphery' approach that balances strategic and tactical, central and local needs (Heeks, 1999b).

Finally, encouraging an integrated approach will require cultural and structural changes in the Indian public sector to ensure that technology is the servant of reform. Such changes are never quick and so the move to an integrated approach can only be seen as a long-term process. In the interim, such IT-related reform initiatives as do take place in India are likely to remain dominated by isolate and, increasingly, idolise approaches. The true potential of information technology will therefore remain untapped in most cases, with initiatives undershooting in their delivery of reform objectives. 


\section{REFERENCES}

Anthes, G. H. (1993). 'Stat tool weeds out bid-rigging companies', Computerworld, 27(27), 58.

Ballantine, J. and Cunningham, P. (1999). 'Strategic information systems planning: applying private sector frameworks in UK public healthcare', in R.B. Heeks (ed.), Reinventing Government in the Information Age, Routledge, London.

Bhatnagar, S.C. (1992). 'Using information technology in rural development: lessons from the Indian experience', in G. Cyranek and S.C. Bhatnagar (eds), Technology Transfer for Development, Tata McGraw-Hill, New Delhi.

Bhatnagar, S.C. (1997). 'Information technology-enabled public sector reforms: myth or reality?', paper presented at conference on 'Public Sector Management in the Next Century', University of Manchester, July.

Cooney, M.J. and O'Flaherty, B. (1996). 'Structural change via information technology in the Irish civil service', in M. Odedra-Straub (ed.), Global Information Technology and Socio-Economic Development, Ivy League Publishing, Nashua.

Davies, C.A. (1997). 'The information infrastructure approach for developing countries', paper presented at conference on 'Public Sector Management in the Next Century', University of Manchester, July.

Gebauer, J. and Schad, H. (1998). Building an Internet-Based Workflow System, Working Paper 98-WP-1030, Fisher Center for Management and IT, University of California, Berkeley.

Gosling, P. (1997). Government in the Digital Age, Bowerdean, London.

Guenat, D. (1992). 'Relevance of information technology in development projects', in G. Cyranek and S.C. Bhatnagar (eds), Technology Transfer for Development, Tata McGraw-Hill, New Delhi.

Gupta, M.P. (1996). 'MIS at national level in India: analysis of problems and issues', Vikalpa, 21(3), 3-16.

Heeks, R.B. (1996a). India's Software Industry, Sage, New Delhi.

Heeks, R.B. (1996b). 'Promoting software production and export in developing countries', in E.M. Roche and M.J. Blaine (eds), Information Technology, Development and Policy, Avebury, Aldershot. 
Heeks, R.B. (1998). Management Information and Information Systems, SOAS, University of London, London.

Heeks, R.B. (ed.) (1999a). Reinventing Government in the Information Age, Routledge, London.

Heeks, R.B. (1999b). Centralised vs. Decentralised Management of Public Information Systems: A Core-Periphery Solution, ISPSM Working Paper no.7, IDPM, University of Manchester, Manchester. http://www.man.ac.uk/idpm/

Heeks, R.B. and Bhatnagar, S.C. (1999). 'Understanding success and failure in information age reform', in R.B. Heeks (ed.), Reinventing Government in the Information Age, Routledge, London.

Isaac-Henry, K. (1997). 'Management of information technology in the public sector', in K. Isaac-Henry et al. (eds), Management in the Public Sector, International Thomson Business Press, London.

Jain, R. (1994). 'MIS for India's literacy programme', Information Technology in Developing Countries, 4(1), 6-8.

Jain, R. and Raghuram, G. (1992). 'Implementation of the Operations Information System: the case of Indian Railways', in S.C. Bhatnagar and M. Odedra (eds), Social Implications of Computers in Developing Countries, Tata McGraw-Hill, New Delhi.

Korac-Kakabadse, A., Korac-Kakabadse, N., and Myers, A. (1996). 'Leadership and the public sector: an internationally comparative benchmarking analysis', Public Administration and Development, 16, 377-396.

Kraemer, K.L., Dutton, W.H., and Northrop, A. (1981). The Management of Information Systems, Columbia University Press, New York.

Madon, S. (1993). 'Introducing administrative reform through the application of computer-based information systems: a case study in India', Public Administration and Development, 13, 37-48.

Madon, S. and Sahay, S. (1996). 'Geographic information systems for development planning in India: challenges and opportunities', in M. Odedra-Straub (ed.), Global Information Technology and Socio-Economic Development, Ivy League Publishing, Nashua.

Mundy, D., Kanjo, C., and Mtema, P. (1999). 'Meeting training needs for information age reform: shortcomings of current training provision', in R.B. Heeks (ed.), Reinventing Government in the Information Age, Routledge, London. 
Naidu, N.C. (1997). IT Strategy Group in Andhra Pradesh, personal communication with author.

Peterson, S.B. (1998). 'Saints, demons, wizards and systems: why information technology reforms fail or underperform in public bureaucracies in Africa', Public Administration and Development, 18, 37-60.

Raman, K.S. and Yap, C.S. (1996). 'From a resource rich country to an information rich country', Information Technology for Development, 7(3), 109-131.

Ramani, K.V. (1994). 'A DSS improves productivity in Indian Railways', Information Technology in Developing Countries, 4(3), 3-4.

Rama Rao, T.P. (1990). 'Decision support systems for development', in S.C. Bhatnagar and N. Bjorn-Andersen (eds), Information Technology in Developing Countries, North Holland, Amsterdam.

Sauer, C. (1993). Why Information Systems Fail: A Case Study Approach, Alfred Waller, Henley-on-Thames, UK.

Singh, A. (1990). 'Computerisation of the Indian Income Tax Department', Information Technology for Development, 5(3), 235-251.

Uttamchandani, L.K. (1990). 'Information technology impact: quantitative issues and case studies', in S.C. Bhatnagar and N. Bjorn-Andersen (eds), Information Technology in Developing Countries, North Holland, Amsterdam.

Wallis, J. and Dollery, B. (1997). 'An evaluation of leadership as a response to agency failure in the public sector', Public Administration, 75, 247-265. 